GRASAS Y ACEITES 71 (3)

July-September 2020, e370

ISSN-L: 0017-3495

https://doi.org/10.3989/gya.0570191

\title{
Solid phase extraction of $\beta$-sitosterol and $\alpha$-tocopherol from sunflower oil deodorizer distillate using desilicated zeolite
}

\author{
O. Karaoglu ${ }^{\mathrm{a}, \mathrm{b}}$, G. Alpdogan ${ }^{\mathrm{b}}$, I.S. Ozdemir ${ }^{\mathrm{a}}$ and E. Ertas ${ }^{\mathrm{a},}$ \\ ${ }^{a}$ The Scientific and Technological Research Council of Turkey - TUBITAK, Food Institute, 41470, Kocaeli/Turkey \\ ${ }^{b}$ Yildiz Technical University, Chemistry Department, Davutpasa Campus, 34220, Istanbul/ Turkey \\ Corresponding author: erdal.ertas@tubitak.gov.tr
}

Submitted: 21 May 2019; Accepted: 17 September 2019; Published online: 26 August 2020

\begin{abstract}
SUMMARY: In this study, the efficiency of using zeolite-based adsorbents in a solid phase extraction (SPE) procedure of $\alpha$-tocopherol and $\beta$-sitosterol isolation from Sunflower Oil Deodorizer Distillate (SuDOD) without pre-treatment was investigated. The results showed that $99.2 \% \alpha$-tocopherol and $97.3 \% \beta$-sitosterol were successfully isolated as pure fractions from SuDOD, when desilicated ZSM-5-type zeolite (DSiZSM-5) was used as adsorbent on a SPE. A simple and rapid HPLC method for simultaneous $\alpha$-tocopherol and $\beta$-sitosterol analysis was developed and validated according to AOAC guidelines. It was found that the inclusion of a DSiZSM-5 SPE step increased the precision of the $\alpha$-tocopherol and $\beta$-sitosterol analysis. In conclusion, DSiZSM- 5 zeolite was proven to be an efficient adsorbent which can be used not only for the recovery of $\alpha$-tocopherol and $\beta$-sitosterol from SuDOD in industrial scale, but also in a laboratory scale clean-up method prior to the analysis of $\alpha$-tocopherol and $\beta$-sitosterol.
\end{abstract}

KEYWORDS: SPE; Sterol; Sunflower oil deodorizer distillate; Tocopherol; Zeolite

RESUMEN: Extracción en fase sólida de $\beta$-sitosterol y $\alpha$-tocoferol de destilados de aceite de girasol desodorizado utilizando zeolita desilicada. En este estudio, se investigó la eficacia del uso de adsorbentes a base de zeolita en el procedimiento de extracción en fase sólida (EFS) para el aislamiento de $\alpha$-tocoferol y $\beta$-sitosterol a partir de destilados de aceites de girasol desodorizados (SuDOD) sin ningún tratamiento previo. Los resultados mostraron que el 99,2\% de $\alpha$-tocoferol y el 97,3\% de $\beta$-sitosterol se aislaron con éxito como fracciones puras de SuDOD, cuando se usó zeolita de tipo ZSM-5 desilicado (DSiZSM-5) como adsorbente en una EFS. Se desarrolló y validó un método HPLC simple y rápido para el análisis simultáneo de $\alpha$-tocoferol y $\beta$-sitosterol de acuerdo con las directrices de la AOAC. Se encontró que la inclusión del paso DSiZSM-5 EFS aumentó la precisión del análisis de $\alpha$-tocoferol y $\beta$-sitosterol. En conclusión, se demostró que la zeolita DSiZSM- 5 es un adsorbente eficiente que puede usarse, no solo para la recuperación de $\alpha$-tocoferol y $\beta$-sitosterol de SuDOD a escala industrial, sino también en un método de limpieza a escala de laboratorio antes del análisis de $\alpha$-tocoferol y $\beta$-sitosterol.

PALABRAS CLAVE: Destilado de aceite de girasol desodorizado; EFS; Esteroles; Tocoferol; Zeolita

ORCID ID: Karaoglu O https://orcid.org/0000-0003-1670-2085, Alpdogan G https://orcid.org/0000-0002-8433-4352, Ozdemir IS https://orcid.org/0000-0002-6159-0847, Ertas E https://orcid.org/0000-0002-9736-0824

Citation/Cómo citar este artículo: Karaoglu O, Alpdogan G, Ozdemir IS, Ertas E. 2020. Solid phase extraction of $\beta$-sitosterol and $\alpha$-tocopherol from sunflower oil deodorizer distillate using desilicated zeolite. Grasas Aceites 71 (3), e370. https://doi.org/10.3989/gya.0570191

Copyright: (C2020 CSIC. This is an open-access article distributed under the terms of the Creative Commons Attribution 4.0 International (CC BY 4.0) License. 


\section{INTRODUCTION}

The recovery of valuable bioactive compounds from the by-products and wastes generated during food processing has become an extremely important strategy for the valorization of food wastes (Martins et al., 2017). The wastes generated during the vegetable oil refining processes has attracted considerable attention as they contain significant amounts of such biomolecules, for instance, sterols, tocopherols, squalene and unsaturated fatty acids which have many applications in the food and pharmaceutical industries (Socaci et al., 2017). Deodorization distillate is regarded as the most significant source of valuable compounds among the various wastes produced during the oil refining process (Yan et al., 2012).

Different methods have been used in the literature to recover and test precious substances from the deodorizer distillate during the refining of vegetable oil. These methods include solid phase extraction (SPE) (Li et al., 2008; Alghamdi et al., 2018), liquidliquid extraction (Ghosh et al., 1996), esterification/ transesterification (Gunawan et al., 2009), molecular distillation (Vazquez et al., 2006) and crystallization (Jiang et al., 2006) for extraction, separation and purification (Moreira et al., 2004). The most important considerations for determining the industrial applicability of the methods mentioned above are efficiency, simplicity and economic cost. In this regard, SPE is the most frequently used method among other separation techniques, in both micro and large scale because of its low cost and effectiveness (Reyes-Garces et al., 2018).

In SPE, the selection of the material used as adsorbing solid phase is the most critical factor which affects the separation performance for the target compound in the most cost-effective way (Maya et al., 2018). Therefore, although they are cheap and highly abundant materials, no research has been carried out yet concerning the usage of zeolites for the recovery of valuable biomolecules from vegetable oil deodorizer distillates.

Zeolites are widely used for the shape-selective separation of molecules, a property which is mainly attributed to its porous structure and interaction with target molecules (Gounaris et al., 2008). It has also been reported that restricted access to, and/ or diffusional constraints within their micropores might limit the adsorption capacity of the zeolites (Verboekend et al., 2011). Therefore, the modification of the microporous structure in a way to buildup the mesoporous frameworks has been proposed to facilitate the access to the micropores which possess active sites. Among the different methods applied, the desilication of zeolites with alkaline treatment has been proposed as one the most efficient and easy ways to create a mesoporous framework within zeolites. (Le Van Mao et al., 1995) reported that alkaline treatment caused an increase in the $\mathrm{Al}$ content of ZSM-5 and enhanced ion exchange capacity.

Therefore, in this study, we investigated the potential of using zeolites (raw and desilicated) in the solid phase extraction cartridge (SPE) for the isolation of $\beta$-sitosterol and $\alpha$-tocopherol from sunflower oil deodorizer distillate (SuDOD) without any pretreatment such as esterification, crystallization, etc. An in-house HPLC method was also developed for the simultaneous determination of $\beta$-sitosterol and $\alpha$-tocopherol by using a UV Vis. detector at 210 $\mathrm{nm}$. The method was validated according to AOAC (Association of Official Analytical Chemists) (2002) guidelines and compared to the reference standards for the determination of $\alpha$-tocopherol and $\beta$-sitosterol.

\section{MATERIALS AND METHODS}

\subsection{Reagents and chemicals}

ZSM-5-type Zeolite with a high silicon content $\left(\mathrm{SiO}_{2} / \mathrm{Al}_{2} \mathrm{O}_{3}\right.$ ratio of $469(\mathrm{Si} / \mathrm{Al}$ 938) $)$ and $\beta$-sitosterol $(75 \%)$ were purchased from Acros Organics (Geel, Belgium). DL- $\alpha$-tocopherol was donation from Supelco (Bellefonte, U.S.A). Hexane (HPLCIsocratic grade), heptane and sodium sulphate were purchased from Carlo Erba Reagents (Milano, Italy); 2-propanol for HPLC and dichloromethane (DCM) were provided by VWR Chemicals (Radnor, Pennsylvania, USA). Potassium hydroxide pellets $(\mathrm{KOH}), \mathrm{N}, \mathrm{O}-\mathrm{Bis}($ trimethylsilyl)trifluoroacetamide, trimethyl chlorosilane, 5- $\alpha$-cholastene-3- $\beta$-ol, tetrahydrofuran (THF) and pyridine were purchased from Merck (Darmstadt Germany). Purified water was obtained using a Milli-Q Plus system (Millipore, Billerica, MA).

In order to separate $\alpha$-tocopherol and $\beta$-sitosterol, standard stock solutions were prepared in hexane at a concentration of $1000 \mathrm{mg} \cdot \mathrm{L}^{-1}$ and stored in amber bottles at a temperature of $-20{ }^{\circ} \mathrm{C}$. Working standard solutions were made by diluting the stock solutions with hexane in volumetric flacks. The following concentrations were obtained: $1,2,5,10,25$, 50 and $100 \mathrm{mg} \cdot \mathrm{L}^{-1}$.

\subsection{SuDOD sample}

The SuDOD samples were obtained from the vegetable oil plant production line of Beta Ziraat A.Ş. (Konya/Turkey). Approximately $1 \mathrm{~kg}$ SuDOD sample was homogenized with a pilot scale mixer at $500 \mathrm{rpm}$ for 15 minutes prior to use in the subsequent studies.

\subsection{Instrumentation}

The HPLC (Agilent 1100 series, USA) system and Gas Chromatograpy (GC) (Perkin Elmer, Autosystem XL, USA) system were used 
throughout this study. The HPLC 1100 system used for chromatographic analyses consisted of a quaternary pump (Agilent, G1311A/USA, serial number DE43630657), an automatic injector (Agilent G1367A WPALS/USA, serial number DE50404041), a column oven (Agilent, G1316A COLCOM/USA, serial number DE43644342), a degasser (Agilent, G1379A/USA, serial number JP40720677) and an UV detector (Agilent 1260 Infinity, G1314F/USA, serial number DEABB00154). Evaluations and quantifications were made on HP ChemStation software B.03.02-SR2 for a liquid chromatographic system. Attenuated total reflection-Fourier transform infrared (ATR-FTIR) spectra of all the Si/ $\mathrm{Al}$ ratio experiments were measured on a Thermo Nicolet 6700 spectrometer FTIR (Nicolet Analytical Instruments, USA), vacuum oven (Nüve EV018, Turkey), solid phase extraction vacuum manifold system (GL Sciences, Japan), Turbovap system (Biotage, Sweden), pilot scale mixer with reactor (Heidolph, Germany) and ultrasound (Bandelin Sonorex, Germany) were used in this study.

\subsection{Solid phase extraction (SPE) of $\alpha$-tocopherol and $\beta$-sitosterol}

For the SPE assays, both ZSM-5 zeolite and its desilicated (DSiZSM-5) form were used as adsorbents. DSiZSM-5 zeolite was synthetized according to the typical method described by Silaghi et al., (2014) which involves treatment of ZSM-5 with 2 $\mathrm{mol} \cdot \mathrm{L}^{-1} \mathrm{KOH}$ as a base catalyzer at $110{ }^{\circ} \mathrm{C}$ for 6 hours. The Si/Al ratio was determined by using a ATR-FTIR spectrometer in order to verify the desilication process. The calculations were carried out by dividing the characteristic pentasil $\mathrm{Si}-\mathrm{O}-\mathrm{Si}$ peak at $540 \mathrm{~cm}^{-1}$ by the total Si-O-Si and Si-O-Al band at $440 \mathrm{~cm}^{-1}$ in the corresponding FTIR spectrum (Gaag et al., 1984). Then, either ZSM-5 or DSiZSM-5 was applied into the SPE cartridge to recover $\alpha$-tocopherol and $\beta$-sitosterol from SuDOD.

For the SPE assays, $1 \mathrm{~g}$ of either ZSM-5 or DSiZSM-5 was added to the $12 \mathrm{~mL}$ SPE cartridge, which was conditioned by passing $30 \mathrm{~mL}$ of hexane through the adsorbent, and $0.25 \mathrm{~mL}$ SuDOD were loaded into the cartridge. The elution of the $\alpha$-tocopherol and $\beta$-sitosterol was achieved by applying a 3 step elution procedure which successively passed $40 \mathrm{~mL}$ of 3 different elution solvents, namely hexane: DCM, 10:1, 5:1 and 1:1 (v:v), through the cartridge at a flow rate of $1.2 \mathrm{~mL} \cdot \mathrm{min}^{-1}$. After each step, elution solvents were collected and concentrated under a gentle stream of nitrogen at $50{ }^{\circ} \mathrm{C}$. Finally, $1 \mathrm{~mL}$ of hexane was added to the residues and they were analyzed for $\alpha$-tocopherol and $\beta$-sitosterol contents. All procedures were performed in triplicate and the samples were injected in duplicate. The amount determined as a percentage of the amount spiked was regarded as the recovery.

\section{5. $\beta$-sitosterol content determination with the reference method}

ISO 12228:1999 was used as the reference standard method for the sterol composition analysis. In this method, $1 \mathrm{~mL} 5 \alpha$-cholestan-3 $\beta$-ol $(1000$ $\mathrm{mg} \cdot \mathrm{L}^{-1}$ ) was added to $0.5 \mathrm{~g}$ of sample as an internal standard. The saponification was carried out with $5.0 \mathrm{~mL}$ saturated methanolic $\mathrm{KOH}$ at $80^{\circ} \mathrm{C}$ for 1 hour. Three successive extractions were carried out with $5 \mathrm{~mL}$ of hexane under nitrogen until reducing the volume of hexane to $10 \mathrm{~mL}$, which was further dried with anhydrous sodium sulphate. $0.5 \mathrm{~mL}$ dried hexane extract was silylated with a solution of 250 $\mu \mathrm{L}$ bis(trimethylsilyl)trifluoroacetamide/trimethylchlorosilane (4:1) and $250 \mu \mathrm{L}$ dry pure pyridine at $60{ }^{\circ} \mathrm{C}$ for $15 \mathrm{~min}$. A Gas Chromatograph equipped with a flame ionization detector (FID) was used for the sterol composition analysis of the SuDOD samples. Separation of the sterols was performed using a SE-54 (5\%-phenyl-1\%vinylmethylpolysiloxane, $30 \mathrm{~m} \times 0.32 \mathrm{~mm} \times 0.25 \mu \mathrm{m})$ column; carrier gas, helium; flow rate, $0.8 \mathrm{~mL} / \mathrm{min}$; injector temperature, $280{ }^{\circ} \mathrm{C}$; detector temperature, $300{ }^{\circ} \mathrm{C}$; oven temperature program, initial temperature was $60^{\circ} \mathrm{C}$ for $2 \mathrm{~min}$, increased at $40^{\circ} \mathrm{C} \cdot \mathrm{min}^{-1}$ to $220^{\circ} \mathrm{C}$, held for $1 \mathrm{~min}$ and then increased at $5{ }^{\circ} \mathrm{C} \cdot \mathrm{min}^{-1}$ to $310^{\circ} \mathrm{C}$, and held for $30 \mathrm{~min}$. $\beta$-sitosterol was identified using the relative retention time (RRT) of $5 \alpha$-cholestan$3 \beta$-ol. Data were collected and quantified with the TotalChrom Navigator software and the results of $\beta$-sitosterol were expressed as $\mathrm{mg} \cdot \mathrm{kg}^{-1}$ of SuDOD.

\section{6. $\alpha$-tocopherol content determination with the reference method}

ISO 9936:2016 was used as the reference standard method for the $\alpha$-tocopherol analysis. According to this method, $1 \mathrm{~g}$ of sample was vortexed for $2 \mathrm{~min}$ with $10 \mathrm{~mL}$ of $\mathrm{n}$-heptane. After filtering through a $0.45 \mu \mathrm{m}$ syringe-filter, the extract was injected into the HPLC-FLD system equipped with a normalphase Luna (Silica $250 \mathrm{~mm}$ x $4.6 \mathrm{~mm} 5 \mu \mathrm{m}$ ) column. The isocratic mobile phase consisted of 3.5\% (volume fraction) THF in $n$-heptane at a flow rate of $1 \mathrm{~mL} \cdot \mathrm{min}^{-1}$. The wavelengths for excitation and emission were $295 \mathrm{~nm}$ and $330 \mathrm{~nm}$, respectively. Data were collected and quantified with Chemstation software and the results were expressed as $\mathrm{mg} \cdot \mathrm{kg}^{-1}$ of SuDOD.

\subsection{HPLC method for the simultaneous determination of $\beta$-sitosterol and $\alpha$-tocopherol contents}

A simultaneous chromatographic analysis of the $\beta$-sitosterol and $\alpha$-tocopherol contents was carried out with the HPLC system. TotalChrom Navigator software was used for the system management and 
data acquisition. Separation was achieved with a normal-phase Luna Silica $250 \mathrm{~mm}$ x $4.6 \mathrm{~mm}$ $5 \mu \mathrm{m}$ i.d.. Three different elution solvents, namely, i) hexane/2-propanol (97/3, v/v), ii) heptane/2-propanol $(97 / 3, \mathrm{v} / \mathrm{v})$ and $\mathrm{iii})$ hexane/2-propanol (99/1, $\mathrm{v} / \mathrm{v}$ ) were tested at a flow rate of $1.0 \mathrm{~mL} \cdot \mathrm{min}^{-1}$ for the best peak separation and geometry. Detection of the $\beta$-sitosterol and $\alpha$-tocopherol was performed with a UV detector set at $210 \mathrm{~nm}$, in accordance with the literature (Czauderna et al., 2009). The retention times of $\beta$-sitosterol and $\alpha$-tocopherol were determined by injecting $25 \mu \mathrm{L}$ of standard solutions containing $50 \mathrm{mg} \cdot \mathrm{L}^{-1} \beta$-sitosterol, $50 \mathrm{mg} \cdot \mathrm{L}^{-1} \alpha$-tocopherol and a mixture solution containing both the $\beta$-sitosterol and $\alpha$-tocopherol at a concentration of $50 \mathrm{mg} \cdot \mathrm{L}^{-1}$ in hexane. The analytical method developed for the determination of $\alpha$-tocopherol and $\beta$-sitosterol in SuDOD was validated according to AOAC Guidelines (AOAC, 2002). Specificity and selectivity, linearity, intraday and interday precision, accuracy, the limits of detection (LOD), and the limit of quantification (LOQ) were used as method validation parameters. Calibration plots were constructed for the two analytes using peak area as a function of the standard concentration of each compound. All analysis and LOD and LOQ of the esterified SuDOD sample were determined in triplicate with successive dilution and considering the signal to noise ratio relative to the background signal as 3 and 10 , respectively. The accuracy was verified by the analysis of the SuDOD sample with the reference methods (ISO, 1999; ISO, 2016).

\section{RESULTS AND DISCUSSION}

\subsection{SPE studies with ZSM-5 and DSiZSM-5}

In order to test the efficiency of zeolites for the isolation of $\alpha$-tocopherol and $\beta$-sitosterol from SuDOD, ZSM-5 zeolite was first used in its ordinary form. The results of the analysis showed that ordinary ZSM-5 zeolite was not efficient in adsorbing and separating $\alpha$-tocopherol and $\beta$-sitosterol in SUDOD samples. The results of the $\alpha$-tocopherol and $\beta$-sitosterol analysis carried out according to reference ISO methods showed that there was no significant difference between the $\alpha$-tocopherol and $\beta$-sitosterol contents of the elutions and almost all the $\alpha$-tocopherol and $\beta$-sitosterol were collected from the first elution.

In order to increase the selectivity of ZSM-5 towards different lipophilic constituents found in SuDOD, we modified the porous structure of the ZSM-5 according to the simple desilication method described by (Silaghi et al., 2014). After the desilication process the $\mathrm{Si} / \mathrm{Al}$ ratio was quantified by comparing the transmittance values of the pentasil Si-O-Si peak at $540 \mathrm{~cm}^{-1}$ to the total $\mathrm{Si}-\mathrm{O}-\mathrm{Si}$ and $\mathrm{Si}-\mathrm{O}-\mathrm{Al}$ band at $440 \mathrm{~cm}^{-1}$ in the corresponding
FTIR spectrum in order to verify the desilication (Figure 1). The results showed that the Si/Al ratio of ZSM-5 decreased from its initial value of 938 to 520 , indicating an efficient desilication. The desilicated ZSM-5-type zeolite (DSiZSM-5) was tested under the same conditions used for the ordinary ZSM-5 zeolite as described in the materials and methods section. It was found that $\alpha$-tocopherol and $\beta$-sitosterol could only be eluted in second and third elution steps with 5:1 and 1:1 Hexane:DCM (v:v), respectively. The results showed that 99.2\% and $97.3 \%$ of the $\alpha$-tocopherol and $\beta$-sitosterol found in SuDOD could be isolated as pure fractions with DSiZSM-5. It was postulated that the metal hydroxyl (Si-OH, Al-OH) groups and the mesoporous framework formed after the desilication of the ZSM-5 (Silaghi et al., 2014) might have increased the molecular interactions and size exclusion capacity of ZSM-5, which enabled the effective separation of the different lipophilic constituents found in SuDOD.

\subsection{HPLC method development studies}

Vegetable oil deodorizer distillates (VoDOD) are complex matrices, which contain various lipophilic constituents. Therefore, in order to eliminate the undesired signals arising from these lipophilic components which interfere with those of $\alpha$-tocopherol and $\beta$-sitosterol, the utilization of different instrumental techniques is required for the accurate identification and quantification of $\alpha$-tocopherol and $\beta$-sitosterol in VoDOD. In reference standard methods, in general, HPLC-FLD and GC-FID systems are suggested to be used for the determination of $\alpha$-tocopherol and $\beta$-sitosterol in VoDOD, respectively.

As it was demonstrated in the previous section, it is possible to obtain high purity $\alpha$-tocopherol and $\beta$-sitosterol fractions void of undesired lipophilic components using DSiZSM-5 SPE. By taking

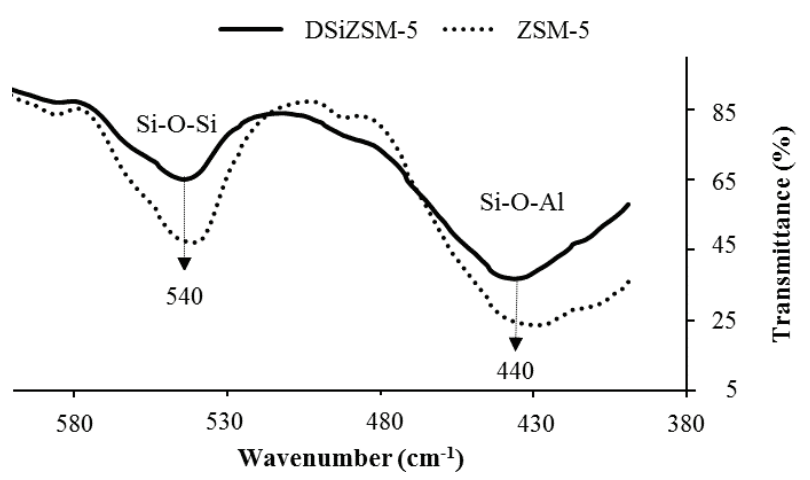

FIGURE 1. FT-IR spectra of pristine ZSM-5 (dotted line) and base $\left(2 \mathrm{~mol} \cdot \mathrm{L}^{-1} \mathrm{KOH}\right)$ treated ZSM-5 (DSiZSM-5; solid line).

The absorbance peaks corresponding to Si-O-Si $\left(540 \mathrm{~cm}^{-1}\right)$ and $\mathrm{Si}-\mathrm{O}-\mathrm{Al}\left(440 \mathrm{~cm}^{-1}\right)$ are marked with arrows on the figure. 
advantage of this purification, we explored the possibility of developing a simple method, without any pre-treatment, which permits the analysis of $\alpha$-tocopherol and $\beta$-sitosterol contents in SuDOD only by using a HPLC-UV system. In this way, it was possible to avoid the cumbersome GC method which includes saponification, extraction and derivatization steps for the sterol analysis.

In the literature, 210 and $294 \mathrm{~nm}$ were reported to be the wavelengths at which the $\beta$-sitosterol (Sheng et al., 2009) and $\alpha$-tocopherol (Renzi et al., 2005) could be best detected, respectively. Therefore, in the present study, 2 different wavelengths, 210 and $295 \mathrm{~nm}$, were investigated for their effectiveness in the simultaneous detection of $\beta$-sitosterol and $\alpha$-tocopherol. The results showed that at $295 \mathrm{~nm}$ the peak of $\alpha$-tocopherol was visible as expected but $\beta$-sitosterol could not be detected. At $210 \mathrm{~nm}$, along with $\alpha$-tocopherol, the $\beta$-sitosterol peak also became visible. The reason for selecting a single wavelength which enabled the simultaneous detection of $\alpha$-tocopherol and $\beta$-sitosterol was to quantify any residual amount of each metabolite which may have existed in pure fractions.

As can be seen in Figure 2, the retention times for $\alpha$-tocopherol and $\beta$-sitosterol were found as 6.3 and $19.8 \mathrm{~min}$, using hexane/2-propanol (99/1, v/v) as the mobile phase, respectively, and each compound gave a specific and clear Gaussian peak shape with a good baseline resolution. In a further attempt to improve the peak separation, geometry and intensity, different elution solvents, namely, $i$ ) hexane/2propanol (97/3, v/v), ii) heptane/2-propanol (97/3, $\mathrm{v} / \mathrm{v})$ and $i i i)$ hexane/2-propanol $(99 / 1, \mathrm{v} / \mathrm{v})$ were also tested. The results showed that the best compromise between the peak separation, geometry and intensity could be obtained with hexane/2-propanol $(99 / 1, \mathrm{v} / \mathrm{v})$ solvent system at $1.0 \mathrm{~mL} \cdot \mathrm{min}^{-1}$ flow rate.
Lastly, the effect of injection volume on the peak areas was determined by injecting 5,10 and $25 \mu \mathrm{L}$ standard mixtures containing $50 \mathrm{mg} \cdot \mathrm{L}^{-1}$ of $\alpha$-tocopherol and $\beta$-sitosterol. As can be seen from Figure 3, the ideal peak width and height for $\beta$-sitosterol and $\alpha$-tocopherol was obtained with $25 \mu \mathrm{L}$ injection volume. According to these results, the optimal conditions for the method validation were defined as: injection volume: $25 \mu \mathrm{L}$; mobile phase: hexane/2-propanol (99/1, v/v); flow rate: $1.0 \mathrm{~mL} \cdot \mathrm{min}^{-1}$; column: $250 \mathrm{~mm} \times 4.6 \mathrm{~mm}, 5 \mu \mathrm{m}$ silica; detection wavelength: $210 \mathrm{~nm}$.

For method validation, the linearity was first studied by using pure $\beta$-sitosterol and $\alpha$-tocopherol standard solutions at five different concentration levels in the range of $5-100 \mathrm{mg} \cdot \mathrm{L}^{-1}$ covering their expected levels in SuDOD. In Table 1, concentration levels in SuDOD samples were expressed in $\mathrm{mg} \cdot \mathrm{kg}^{-1}$ due to the fact that separation and pre-concentration steps were included in the procedure. Table 1 summarizes the characteristics of the calibration graphs obtained for $\beta$-sitosterol and $\alpha$-tocopherol standards. The limit of detection (LOD) and limit of quantification (LOQ) values for $\alpha$-tocopherol and $\beta$-sitosterol were 1.39, 1.19 and 4.62, 3.96, respectively.

The reliability of the method was verified by recovery and repeatability tests. The precision of the method was calculated as both injection (withinday) repeatability and between day reproducibility which was checked on 2 different days at the same concentration levels. The results revealed that the within-day and between-day precision figures are satisfactory at less than $2.14 \%$ and the method provides a precise analysis of the $\beta$-sitosterol and $\alpha$-tocopherol contents of SuDOD. The accuracy of the method was tested upon performing recovery studies and the data for SuDOD samples spiked

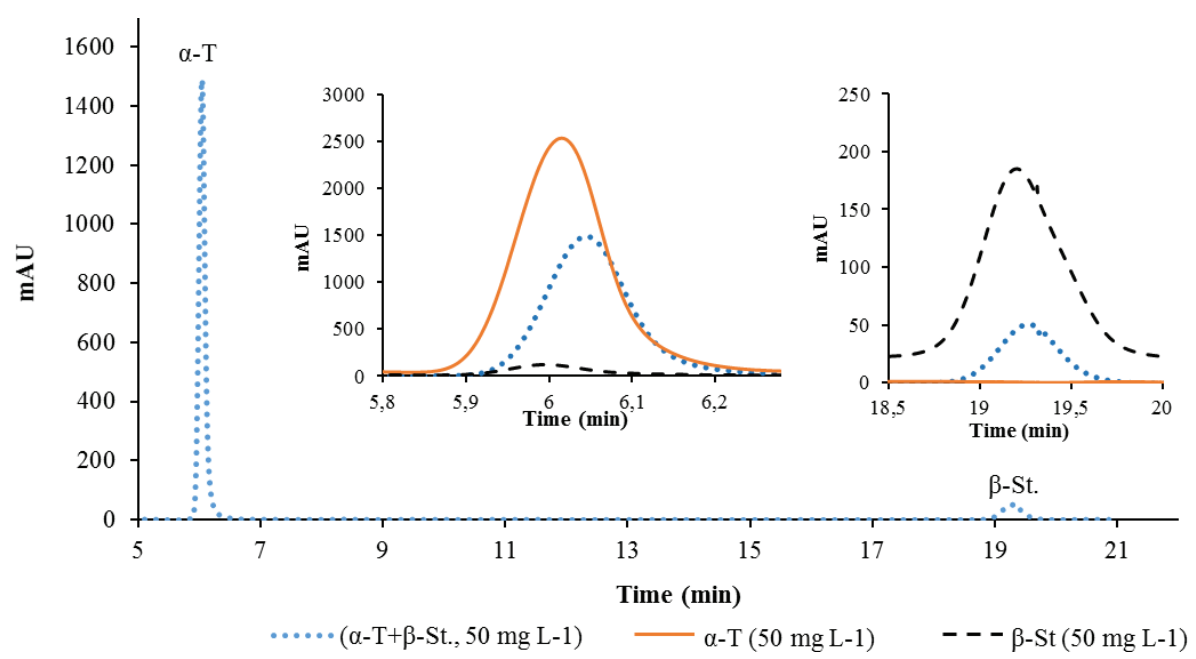

FIGURE 2. The HPLC-UV chromatograms of the standard solutions containing $50 \mathrm{mg} \cdot \mathrm{L}^{-1} \alpha$-tocopherol ( $\alpha$-T, orange solid line), $50 \mathrm{mg} \cdot \mathrm{L}^{-\mathrm{i}} \beta$-sitosterol ( $\beta$-St., dashed black line) and $50 \mathrm{mg} \mathrm{L}-1 \alpha$-tocopherol $+\beta$-sitosterol (blue dashed line) detected at $210 \mathrm{~nm}$. 


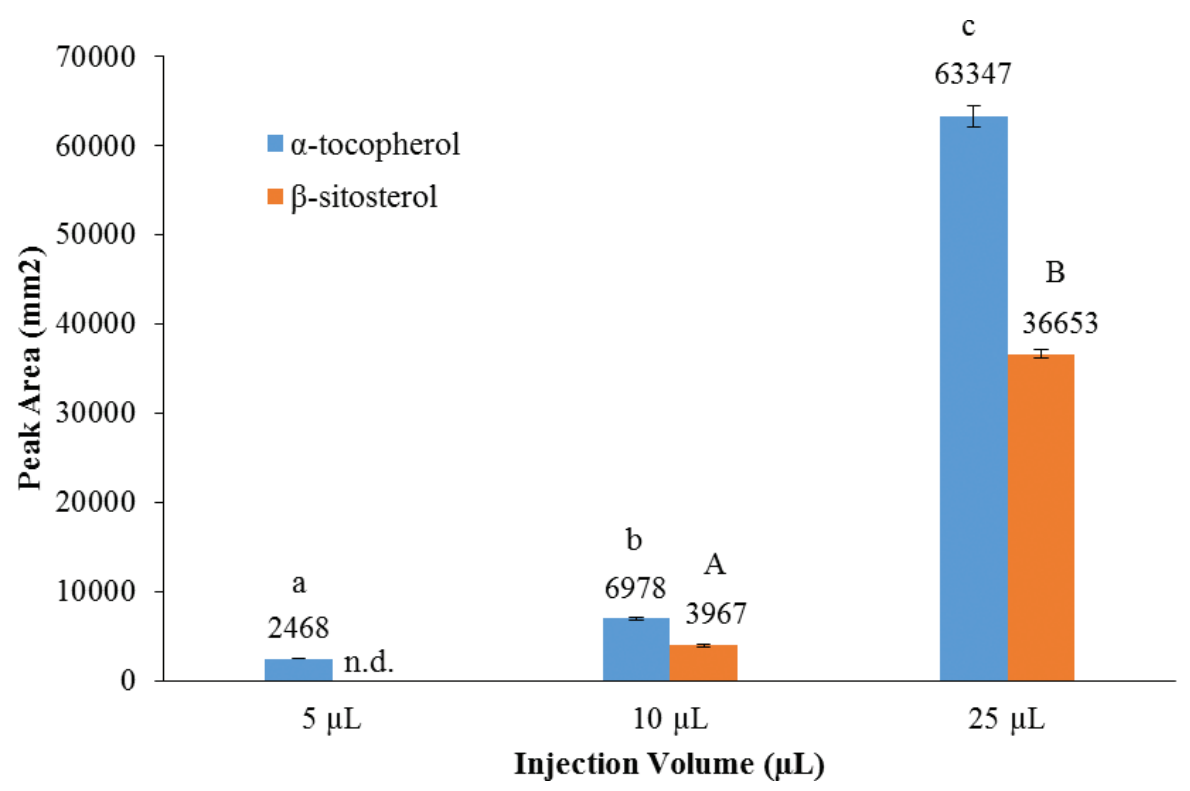

FIGURE 3. $\alpha$-tocopherol and $\beta$-sitosterol peak areas corresponding to different injection volumes. Mean values and corresponding standard deviations $(n=3)$ for each injection are given on the bars. The means with different letters are significantly different $(\mathrm{p}<0.05)$ from each other. (n.d.: not detected).

TABLE 1. The data derived from calibration graphs of compounds obtained by HPLC-UV.

\begin{tabular}{lcc}
\hline Results & $\boldsymbol{\alpha}$-tocopherol & $\boldsymbol{\beta}$-sitosterol \\
\hline Retention Time t $(\mathrm{min})$ & 6.8 & 19.8 \\
Conc. in the vial $\left(\mathrm{mg} \mathrm{L}^{-1}\right)$ & $5-100$ & $5-100$ \\
Conc. in the sample $\left(\mathrm{mg} \mathrm{kg}^{-1}\right)$ & $200-4000$ & $125-2500$ \\
Linear Equation & $\mathrm{y}=(72.35 \pm 1.13) * \mathrm{x}+(29.83 \pm 49.21)$ & $\mathrm{y}=(7.97 \pm 0.14) * \mathrm{x}+(1.44 \pm 6.19)$ \\
Correlation coefficient $\left(\mathrm{R}^{2}\right)$ & 0.9993 & 0.9995 \\
$\operatorname{LOD}^{\mathrm{a}}\left(\mathrm{mg} \mathrm{L}^{-1}\right)$ & 1.39 & 1.19 \\
$\operatorname{LOQ}^{\mathrm{b}}\left(\mathrm{mg} \mathrm{L}^{-1}\right)$ & 4.62 & 3.96 \\
$\operatorname{RSD}^{\mathrm{c}}(\%, \mathrm{n}=3)$ within-day & 0.91 & 0.79 \\
$\left.\operatorname{RSD}^{2} \%, \mathrm{n}=3\right)$ between-day & 2.14 & 2.12 \\
\hline
\end{tabular}

${ }^{\mathrm{a}}$ Limit of Detection, ${ }^{\mathrm{b}}$ Limit of Quantification, ${ }^{\mathrm{c}}$ Relative Standard Deviation.

with different concentrations of standards, which are listed in Table 2.

As shown in Table 2, the recovery values were above $95 \%$ for both analytes and in accordance with the AOAC Guidelines (AOAC, 2002), which dictate recovery values between $95-102 \%$ for the samples containing a minimum of $10 \%$ of the target component.

In order to evaluate the accuracy of the proposed method, the $\alpha$-tocopherol and $\beta$-sitosterol contents of the real industrial SuDOD samples were determined both by reference methods (ISO 9936:2016 for tocopherol, ISO 12228:1999 for sterol) and the in-house HPLC-UV method for the $\alpha$-tocopherol and $\beta$-sitosterol contents (Figure 4). For doing so, SuDOD samples were passed through the DSiZSM-5 SPE cartridge directly and fractions were collected and analyzed.
As can be seen from Table 3, SuDOD samples contain 4.1\% $\alpha$-tocopherol and 5.2\% $\beta$-sitosterol when analyzed according to the conventional (ISO) protocols without SPE. Significantly $(p<0.05)$ lower values, which were checked by t-test, $3.9 \%$ of $\alpha$-tocopherol and $4.9 \%$ of $\beta$-sitosterol, were obtained when the SuDOD samples were passed through the SPE cartridge prior to analyses with reference ISO methods. The SuDOD samples were found to contain even lower values, $3.8 \%$ of $\alpha$-tocopherol and $4.7 \%$ of $\beta$-sitosterol, when analyzed with the inhouse HPLC method after having passed through the SPE cartridge. These results indicated that the utilization of SPE clean-up and the in-house method resulted in lower recovery and sensitivity in analyzing $\alpha$-tocopherol and $\beta$-sitosterol compared to the conventional procedure. However, this minute difference can be ignored in light of the simplicity 
TABLE 2. Recovery data for sunflower oil deodorizer distillate (SuDOD) samples spiked with different concentrations of $\alpha$-tocopherol and $\beta$-sitosterol standards.

\begin{tabular}{|c|c|c|c|}
\hline \multirow[b]{2}{*}{ Analyte } & \multicolumn{2}{|c|}{ Concentration of spiked standard } & \multirow[t]{2}{*}{$\begin{array}{c}\text { Recovery } \pm \text { SD }^{\mathrm{a}} \\
(\%, \mathrm{n}=6)\end{array}$} \\
\hline & $\begin{array}{l}\text { In the vial } \\
\left(\mathrm{mg} \cdot \mathrm{L}^{-1}\right)\end{array}$ & $\begin{array}{c}\text { In the SuDOD sample } \\
\left(\mathrm{mg} \cdot \mathrm{kg}^{-1}\right)\end{array}$ & \\
\hline \multirow[t]{3}{*}{$\alpha$-tocopherol } & 5 & 200 & $97 \pm 3$ \\
\hline & 50 & 2000 & $102 \pm 3$ \\
\hline & 100 & 4000 & $99 \pm 3$ \\
\hline \multirow[t]{3}{*}{$\beta$-sitosterol } & 5 & 125 & $96 \pm 3$ \\
\hline & 50 & 1250 & $97 \pm 2$ \\
\hline & 100 & 2500 & $99 \pm 3$ \\
\hline
\end{tabular}

${ }^{\mathrm{a}}$ Standard Deviation.

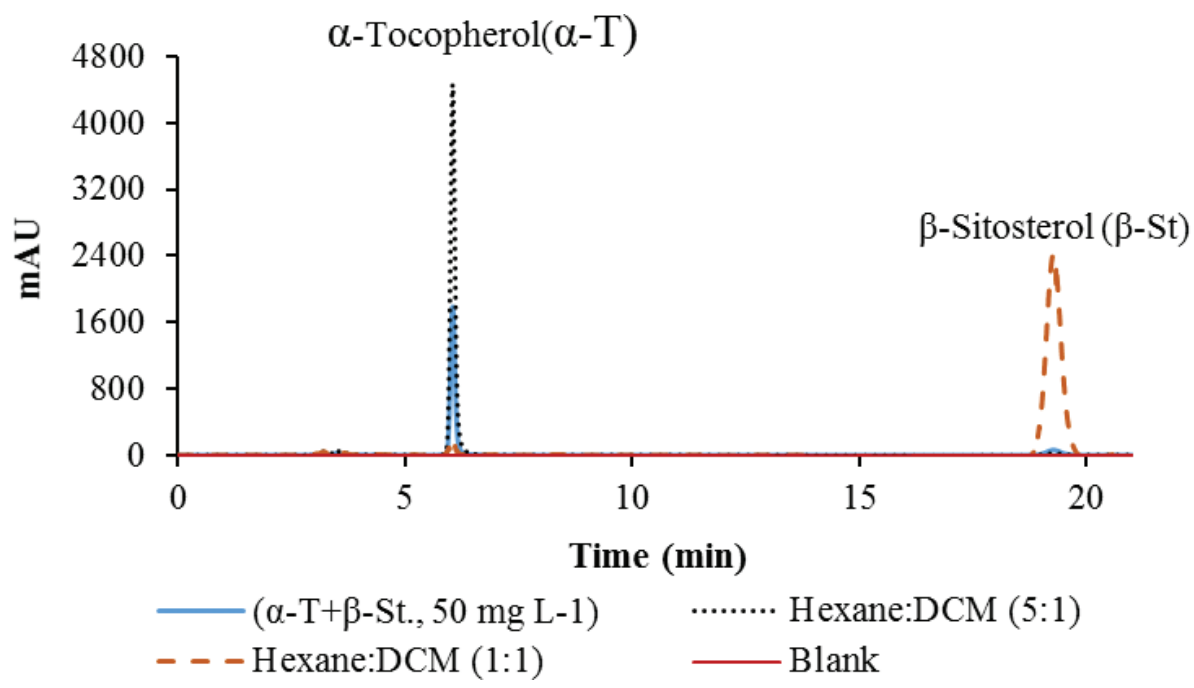

FIGURE 4. Chromatograms of sunflower oil deodizer distillate (SuDOD) samples Hexane:dichloromethane(DCM) (1:1) (orange dashed line) and Hexane:DCM (5:1) (black dashed line), standard solution containing $50 \mathrm{mg} \cdot \mathrm{L}^{-1}$ of $\alpha$-tocopherol $(\alpha-\mathrm{T})$ and $\beta$-sitosterol ( $\beta$-St.) (blue solid line) and blank (red dashed line) sample.

TABLE 3. Comparison of $\alpha$-tocopherol and $\beta$-sitosterol contents of sunflower oil deodorizer distillate (SuDOD) samples treated with or without desilicated ZSM-5 (DSiZSM-5) in solid phase extraction (SPE), determined by using reference and in-house methods.

\begin{tabular}{lccc}
\hline & \multicolumn{2}{c}{ With SPE } & Without SPE \\
\cline { 2 - 4 } Analyte & Reference method & In-house method & Reference method \\
\hline $\boldsymbol{\alpha}$-tocopherol $\left(\mathbf{g} \cdot \mathbf{1 0 0 g ^ { - 1 } )}\right.$ & $3.91^{\mathrm{a}} \pm 0.04$ & $3.82^{\mathrm{a}} \pm 0.14$ & $4.13^{\mathrm{b}} \pm 0.07$ \\
$\boldsymbol{\beta}$-sitosterol $\left(\mathbf{g} \cdot \mathbf{1 0 0 \mathbf { g } ^ { - 1 }}\right)$ & $4.87^{\mathrm{a}} \pm 0.03$ & $4.73^{\mathrm{a}} \pm 0.13$ & $5.23^{\mathrm{b}} \pm 0.06$ \\
\hline
\end{tabular}

${ }^{\mathrm{a}}$ The results were given as mean \pm standard deviation $(\mathrm{n}=3)$. ${ }^{\mathrm{b}}$ In a row, means with the same supercript letters were not significantly different ( $\mathrm{p}>0.05$ ) according to the Student's t-test.

and speed of the method developed in this study which can be considered as a reasonable screening method for laboratories with limited infrastructure and resources.

\section{CONCLUSIONS}

It can be concluded that desilicated ZSM-5 zeolite can be used as an efficient adsorbent in SPE for the isolation of $\alpha$-tocopherol and $\beta$-sitosterol from SuDOD with high purity. The exclusion of lipophilic impurities from the SuDOD in the SPE clean-up procedure also permitted the development of a simple HPLC-UV method for the analysis of $\alpha$-tocopherol and $\beta$-sitosterol. The advantage of using zeolite base adsorbents is that they are more abundant and cheaper than silica and polymeric adsorbents commonly used in SPE. In the future, 
it should be of interest to investigate in detail the effect of desilication and dealumination on the porous structure of the zeolites and their performances in the isolation of target molecules from complex matrices.

\section{ACKNOWLEDGMENTS}

The authors would like to thank TUBITAK (Project No: 215M279) for financial support.

\section{REFERENCES}

Alghamdi EM, Whitcombe MJ, Piletsky SA, Piletska EV. 2018. Solid phase extraction of $\alpha$-tocopherol and other physiologically active components from sunflower oil using rationally designed polymers. Anal. Methods 10, 314-321. https://doi.org/10.1039/C7AY02726E

AOAC 2002. AOAC Guidelines for Single Laboratory Validation of Chemical Methods for Dietary Supplements and Botanicals.

Czauderna M, Kowalczyk J, Niedzwiedzka KM. 2009. Simple HPLC Analysis of Tocopherols and Cholesterol from Specimens of Animal Origin. Chem. Anal. (Warsaw) 54, 203-214.

Gaag FJ, Bekkum HV. 1984. Identification of ZSM-type and other 5-rin 1 containing zeolites by i.r. spectroscopy. Zeolites 4 (4), 369-372. https://doi.org/10.1016/0144-2449(84)90013-7

Gounaris EC, Wei J, Floudas AC. 2008. Shape Selective Zeolite Separation and Catalysis: Optimization Methods. Encyclopedia of Optimization. Springer, Boston, MA. https://doi.org/10.1007/978-0-387-74759-0 603

Ghosh S, Bhattacharyya D. 1996. Isolation of tocopherol and sterol concentrate from sunflower oil deodorizer distillate. J. Am. Oil Chem. Soc. 73, 1271-1274. https://doi. org/10.1007/BF02525456

Gunawan S, Ju Y. 2009. Vegetable Oil Deodorizer Distillate: Characterization, Utilization and Analysis. Sep. Purif. Rev. 38, 207-241. https://doi.org/10.1080/15422110903095151

ISO 1999. Animal and vegetable fats and oils - Determination of individual and total sterols contents - Gas chromatographic method.

ISO 2016. Animal and vegetable fats and oils - Determination of tocopherol and tocotrienol contents by high-performance liquid chromatography.

Jiang S, Shao P, Pan L, Zhao Y. 2006. Molecular distillation for recovering tocopherol and fatty acid methyl esters from rapeseed oil deodoriser distillate. Biosyst. Eng. 93, 383-391. https://doi.org/10.1016/j.biosystemseng.2006.01.008
Le Van Mao R, Ramsaran A, Xiao S, Yao J, Semmer V. 1995. $\mathrm{pH}$ of the Sodium-Carbonate Solution Used for the Desilication of Zeolite Materials. J. Mater. Chem. 5, 533-535. https://doi.org/10.1039/JM9950500533

Li M, Pham PJ, Pittman JCU, Li T. 2008. Selective Solid-Phase Extraction of $a$-Tocopherol by Functionalized Ionic Liquid-modified Mesoporous SBA-15 Adsorbent. Anal. Sci. 24, 1245-1250. https://doi.org/10.2116/analsci.24.1245

Martins Z, Pinho O, Ferreira I. 2017. Food industry by-products used as functional ingredients of bakery products. Trends Food Sci. Technol. 67, 106-128. https://doi.org/10.1016/j. tifs.2017.07.003

Maya F, Cabello C, Ghani M, Palomino G, Cerda V. 2018. Emerging materials for sample preparation. J. Sep.Sci. 41, 262-287. https://doi.org/10.1002/jssc.201700836

Moreira EA, Baltanas, MA. 2004. Recovery of phytosterols from sunflower oil deodorizer distillates. J. Am. Oil Chem. Soc. 81, 161-167. https://doi.org/10.1007/ s11746-004-0875-x

Renzi M, Righi F, Quarantelli C, Quarantelli A, Bonomi A. 2005. Simplified HPLC-UV method for the determination of \pm -tocopherol in plasma. Italian Journal of Animal Science 4, 191-195. https://doi.org/10.4081/ ijas.2005.191

Reyes-Garces N, Gionfriddo E, Gomez-Rios G, Alam M, Boyaci E, Bojko B, Singh V, Grandy J, Pawliszyn J. 2018. Advances in Solid Phase Microextraction and Perspective on Future Directions. Anal. Chem. 90, 302-360. https:// doi.org/10.1021/acs.analchem.7b04502

Sheng Y, Chen XB. 2009. Isolation and identification of an isomer of $\beta$-sitosterol by HPLC and GC-MS. Health 1, 203-206. https://doi.org/10.4236/health.2009.13034

Silaghi M, Chizallet C, Raybaud P. 2014 . Challenges on molecular aspects of dealumination and desilication of zeolites. Microporous Mesoporous Mater. 191, 82-96. https://doi. org/10.1016/j.micromeso.2014.02.040

Socaci SA, Farcas AC, Vodnar DC, Tofana M. 2017. Food Wastes as Valuable Sources of Bioactive Molecule. Superfood and Functional Food-The Development of Superfoods and Their Roles as Medicine. Rijeka, Croatia: InTech. 75-93. https://doi.org/10.5772/66115

Vazquez L, Torres C, Fornari T, Grigelmo N, Senorans F, Reglero G. 2006. Supercritical fluid extraction of minor lipids from pretreated sunflower oil deodorizer distillates. Eur. J. Lipid Sci. and Technol. 108, 659-665. https://doi. org/10.1002/ejlt.200600035

Verboekend D, Perez-Ramirez J. 2011. Design of hierarchical zeolite catalysts by desilication. Catal. Sci. Technol. 1, 879-890. https://doi.org/10.1039/C1CY00150G

Yan F, Yang H, Li J, Wang H. 2012. Optimization of phytosterols recovery from soybean oil deodorizer distillate. J. Am. Oil Chem. Soc. 89, 1363-1370. https://doi.org/10.1007/ s11746-012-2023-0 